\title{
PENILAIAN KEMAHIRAN MENTAL KE ARAH PRESTASI CEMERLANG ATLET BOLING TEN-PIN MSSM 2018 NEGERI PERAK
}

\author{
Nur Haziyanti Mohamad Khalid ${ }^{1}$, Norazam Mat $\mathrm{Isa}^{2} \&$ Mazura A. Fadhil ${ }^{3}$ \\ ${ }^{1}$ Fakulti Sains Sukan dan Kejurulatihan, Universiti Pendidikan Sultan Idris, \\ Tanjong Malim, Perak, Malaysia \\ ${ }^{2}$ Jabatan Pendidikan Negeri Perak, Malaysia \\ ${ }^{3}$ SMK Convent, Teluk Intan, Perak, Malaysia \\ Jurnal Sains Sukan dan Pendidikan Jasmani 7(2): 45-55, Received: 3 September 2018, \\ Accepted: 1 October 2018
}

\begin{abstract}
Abstrak
Kajian ini bertujuan mengenal pasti tahap kemahiran mental dalam kalangan atlet pelajar sekolah. Kajian dilakukan secara tinjauan terhadap 24 pemain boling ten-pin yang mewakili negeri Perak dalam kejohanan Majlis Sukan Sekolah Malaysia 2018. Soal selidik Sport Personality Questionnaire (SPQ20) digunakan bagi mengukur 20 dimensi kemahiran mental yang terdiri daripada empat domain utama iaitu pencapaian dan persaingan, keyakinan dan resilien, interaksi dan semangat kesukanan, serta kuasa dan keagresifan. SPQ20 juga menentukan kecenderungan atlet terhadap matrik kemahiran mental dan potensi kepimpinan. Analisis deskriptif adalah berdasarkan pendekatan sistem RAG (Red, Amber, Green) Traffic Light. Dapatan kajian menunjukkan keseluruhan domain kemahiran mental berada pada tahap kuning (sederhana). Berdasarkan matrik kemahiran mental, paling ramai atlet berada dalam golongan confident achiever (54.2\%). Berdasarkan matrik potensi kepimpinan pula, paling ramai atlet berada dalam golongan democratic captain (33.3\%). Kajian ini menggambarkan kepentingan menilai tahap kemahiran mental atlet, cara penggunaan alat ukur yang bersesuaian bagi mendapatkan maklumat berkaitan tahap kemahiran mental, dan cara pelaporan dapatan kajian bagi tujuan penambahbaikan aspek kejurulatihan.
\end{abstract}

Kata Kunci: Sport Personality Questionnaire (SPQ20), Personaliti Sukan, Kemahiran Mental, Atlet Sekolah, Kejurulatihan 


\title{
MENTAL SKILL ASSESSMENT TOWARDS EXCELLENT ACHIEVEMENT AMONG MSSM 2018 PERAK TEN-PIN BOWLING ATHLETES
}

\begin{abstract}
This research was conducted to determine the mental skill among school athletes. This research was conducted using survey method among 24 ten-pin bowlers that represented Perak in the Majlis Sukan Sekolah Malaysia (MSSM) 2018 tournament. Sport pErsonality Questionnaire (SPQ20) questionnaire was used to measure the 20 mental skill dimensions that consisted of 4 main domains that are achievement and competitiveness, confidence and resilience, interaction and sportsmanship, and power and aggression. SPQ20 also determine the athletes' trend on the mental skill matric and leadership potential. Descriptive analysis is based on the Red, Amber, Green (RAG) Traffic Light system approach. Results showed all the mental skill domains were at the yellow level (intermediate). Based on the mental skill metric, highest number of athletes were in the confident achiever group (54.2\%). Based on the leadership potential matric, highest number of athletes were in the democratic captain group (33.3\%). The research demonstrate the importance of evaluating the athletes' mental skill level, methods on using suitable measuring tools to gain information on the mental skill level, and the way to report results of study in order to enhance coaching aspect.
\end{abstract}

Keywords: Sport Personality Questionnaire (SPQ20), Sports’ personality, mental skill, school athlete, coaching

\section{PENGENALAN}

Cabaran dalam aktiviti sukan merangkumi aspek fizikal dan psikologi wujud disebabkan oleh kepelbagaian faktor yang dihadapi atlet seperti kompetensi instrumental, rangsangan persekitaran dan kehendak persembahan, ciri-ciri peribadi dan tingkah laku regulasi kendiri (Gardner \& Moore, 2006). Justeru aspek persediaan dan kekuatan mental memainkan peranan penting dalam latihan sukan di samping aspek kemahiran fizikal itu sendiri Noakes (2003). Kajian terdahulu juga menunjukkan kemahiran mental sangat membantu atlet mencapai prestasi yang optimum (Hardy, Jones \& Gould, 1996). Setiap jenis sukan mengandungi ciri-ciri fizikal dan teknikal yang memerlukan atlet memiliki kemahiran khusus. Ciri-ciri ini jugalah yang memberi implikasi terhadap penggunaan kemahiran mental dalam kalangan atlet (Taylor, 1993).

Banyak faktor psikologi yang boleh dijadikan penentu terhadap peningkatan prestasi atlet. Butt et al. (2010) menjelaskan kepentingan kerja keras, motivasi dan keupayaan untuk beraksi di bawah tekanan sebagai penentu utama prestasi. Kruger, Pienaar, Plessis, dan Van Rensburg (2012) dan Hollings, Mallett, dan Hume (2014) pula melihat kepentingan penetapan matlamat dalam 
persembahan sukan, serta komitmen yang signifikan diperlukan ke arah menjadikan matlamat sebagai satu kenyataan. Terdapat peringkat kemahiran mental yang merujuk kepada tahap penglibatan atlet. Atlet elit memerlukan kemahiran psikologi yang membantu proses daya tindak terhadap cabaran perlawanan (Jones et al., 2002). Kebiasaannya, atlet elit dilihat sebagai individu yang bermotivasi dan mempunyai keyakinan yang lebih tinggi, lebih fokus dan sentiasa bersedia secara mental berbanding atlet biasa. Atlet yang berjaya pula cenderung untuk menjadi lebih fokus, yakin dan terkawal walaupun tekanan dan tuntutan cabaran sukan diletakkan ke atas mereka. Manakala atlet sukan berpasukan menunjukkan skor yang tinggi dalam motivasi dan kawalan kebimbangan berbanding atlet sukan individu (Elferink-Gemser, Visscher, Lemmink \& Mulder, 2004).

Gould et al (2002) menjelaskan bahawa persediaan mental adalah strategi kognitif, emosi dan tingkah laku yang digunakan oleh atlet untuk meningkatkan kemahiran mental bagi mencapai prestasi puncak sama ada ketika latihan dan pertandingan. Antara strategi yang sering digunakan dalam konteks persediaan mental adalah seperti regulasi kebangkitan, imageri, strategi peningkatan tumpuan, keyakinan diri, motivasi, komitmen dan penetapan matlamat (Weinberg \& Gould, 2011). Kajian menunjukkan kombinasi latihan mental dan fizikal memberi kesan yang lebih signifikan berbanding jika hanya melakukan latihan fizikal semata-mata (Hardy, Jones \& Gould, 1996; Weinberg \& Gould, 2011; Orlick, 2000; Pieterse \& Potgieter, 2006; Hodge, 2007; dan Kumar \& Shirotriya, 2010).

Berdasarkan beberapa kajian terhadap para pemenang di sukan Olimpik, Gould et al. (2002) mendapati ciri-ciri kemahiran mental atlet sukan Olimpik adalah terdiri daripada keupayaan daya tindak, kawalan kebimbangan, tahap keyakinan yang tinggi, kecerdasan sukan, harapan, optimis dan kesempurnaan yang terkawal, mempamerkan sifat persaingan dan memiliki etika kerja yang kuat. Penggunaan kaedah imageri, ketabahan dan keyakinan juga sangat berhubungkait dengan kejayaan khususnya bagi atlet olahraga dalam sukan Olimpik (Vernacchia et al., 2000). Fletcher dan Sarkar (2012) pula mendapati bahawa faktor psikologi seperti personaliti, motivasi, keyakinan, fokus dan persepsi terhadap sokongan sosial dapat melindungi atlet terbaik dunia daripada mengalami kesan negatif akibat stress. Menurut penyelidik, faktor tersebut membantu atlet berfikir dan bertindak balas terhadap cabaran.

Beberapa reka bentuk aspek kemahiran mental turut ditemui dalam kajian psikologi sukan. Menurut Jones et al. (2007), kemahiran mental mengandungi dua elemen utama iaitu pertama, keupayaan atau sikap umum yang membolehkan atlet menangani dan mengimbangi cabaran sukan dan kehidupan. Manakala kedua, adalah strategi psikologi atau kemahiran mental utama yang menghasilkan kejayaan prestasi secara konsisten. Jones et al. (2007) menyenaraikan ciri-ciri yang terhasil daripada dua elemen kemahiran mental iaitu percaya diri sendiri, keinginan dan motivasi, fokus prestasi, faktor berkaitan kehidupan, menangani tekanan, kebimbangan dan kesukaran dalam persembahan. Selain itu, Clough et al. (2002) memperkenalkan reka bentuk kekuatan mental dalam enam aspek utama iaitu cabaran, komitmen, kawalan emosi, kawalan kehidupan, keyakinan diri, dan interpersonal. Lesyk's (1998) pula memperkenalkan reka bentuk kemahiran mental atlet juara mengandungi sembilan jenis kemahiran dalam tiga tahap berbeza. Tahap pertama mengandungi 
kemahiran sikap, motivasi, penetapan matlamat dan kemahiran sosial, sebagai asas kepada pembentukan atlet yang sempurna. Tahap kedua pula mengandungi kemahiran bicara kendiri dan imageri mental sebagai langkah dalam persediaan dan latihan. Manakala tahap tiga mengandungi kemahiran menangani tekanan, emosi dan konsentrasi, iaitu kemahiran penting dalam fasa perlaksanaan dan persembahan.

Walaubagaimanapun, kefahaman tentang keberkesanan kemahiran mental ke atas prestasi, dan kepentingan latihan mental untuk meningkatkan prestasi masih kurang dalam kalangan atlet, jurulatih dan pentadbir sukan (Gee, 2010). Terdapat ramai jurulatih yang masih menganggap bahawa latihan kemahiran psikologi adalah untuk atlet yang bermasalah sahaja dan bukannya sebahagian daripada strategi peningkatan prestasi (Nelson, 2008). Justeru, ahli psikologi sukan perlu lebih efektif dalam psiko-pendidikan atlet dan jurulatih tentang mekanisma yang boleh mempengaruhi prestasi. Hakikatnya, selain daripada peranan yang dimainkan oleh ahli psikologi sukan, jurulatih juga merupakan individu yang sangat relevan sebagai pelaksana latihan kemahiran psikologi dan pengkaji secara saintifik berkenaan faktor yang mempengaruhi tingkah laku dan prestasi atlet (Weinberg \& Gould, 2011).

Banyak cara boleh digunakan untuk melakukan penilaian dan diagnosis terhadap ciri-ciri dan prestasi atlet. Penilaian juga dilakukan bagi mengenal pasti tahap kemahiran dan kekuatan mental. Maklumat terhadap ciri-ciri kemahiran psikologi dan prestasi adalah penting bagi tujuan diagnosis dan pemilihan strategi latihan kemahiran psikologi (Porter, 2003). Salah satu alat yang dapat mengukur kekuatan dan kemahiran mental atlet ialah Sport Personality Questionnaire (SPQ20) (MySkillProfile, 2016). SPQ20 memberi gambaran luas mengenai keseluruhan kekuatan mental, keyakinan diri dan resilien, etika dan motif kerja, kemahiran sosial, prinsip etika dan penggunaan teknik peningkatan prestasi dalam kalangan atlet. SPQ20 dibina berdasarkan reka bentuk kemahiran mental yang mengandungi empat domain utama iaitu pencapaian dan persaingan, keyakinan dan resilien, interaksi dan semangat kesukanan, serta kuasa dan keagresifan. Melalui SPQ20, kefahaman terhadap ciri-ciri atlet dapat dibina bagi membantu aspek kejurulatihan atlet. SPQ20 juga menyediakan ruang perbincangan mengenai hubungkait tret personaliti dan kemahiran mental, memudahkan proses kejurulatihan atlet dengan menggabungkan faktor fizikal dan mental, mengenal pasti faktor penyebab kelemahan prestasi, dan menggalakkan perkembangan prestasi personal yang lebih efektif.

Sehubungan itu, kajian telah dijalankan dengan melaksanakan SPQ20 ke atas sekumpulan atlet pelajar bawah 17 tahun yang mewakili negeri Perak, Malaysia, bagi acara Boling Ten-Pin di kejohanan sukan Majlis Sukan Sekolah Malaysia 2018. Objektif kajian adalah untuk mengenal pasti tahap kemahiran mental dalam empat domain utama iaitu pencapaian dan persaingan, keyakinan dan resilien, interaksi dan semangat kesukanan, serta kuasa dan keagresifan. Selain itu, kajian ini juga bertujuan mengenal pasti kecenderungan ciri-ciri atlet berdasarkan matrik kemahiran mental dan potensi kepemimpinan. Hasil kajian ini menyediakan laporan berkaitan perkembangan kemahiran mental atlet dan cadangan penambahbaikan dari aspek latihan kemahiran mental terhadap atlet dan jurulatih, serta pihak pengurusan pasukan. 


\section{METODOLOGI KAJIAN}

\section{Reka Bentuk Kajian}

Kajian ini menggunakan reka bentuk kajian tinjauan bagi mendapatkan maklumat mengenai tahap kekuatan dan kemahiran mental atlet. Kajian tinjauan sesuai digunakan kerana tujuan penyelidik hanyalah untuk memungut sejumlah maklumat menggunakan kaedah soal selidik bagi menghuraikan objektif kajian (Ary, Jacobs, \& Razavieh, 2010).

\section{Subjek Kajian}

Jumlah keseluruhan subjek adalah seramai 24 orang. Subjek terdiri daripada semua atlet berumur bawah 12, 15 dan 18 tahun yang mewakili acara Boling Ten-Pin dalam kejohanan sukan Majlis Sukan Sekolah Malaysia 2018 (MSSM 2018). Semasa kajian dijalankan, subjek sedang dalam fasa persediaan bagi menghadapi kejohanan MSSM 2018 dalam pelbagai peringkat acara Tenpin Boling seperti acara individu bawah 12, 15 dan 18 (lelaki dan perempuan), beregu bawah 12, 15 dan 18 (lelaki dan perempuan), trio bawah 12, 15 dan 18 (lelaki dan perempuan), all event bawah 12, 15 dan 18 (lelaki dan perempuan), berpasukan bawah 12, 15 dan 18 (lelaki dan perempuan), dan master / step ladder bawah 12, 15 dan 18 (lelaki dan perempuan).

\section{Instrumen Kajian}

Kajian ini menggunakan Sport Personality Questionnaire (SPQ20) (MySkillProfile, 2016) sebagai instrumen utama bagi mendapatkan maklumat mengenai aspek kekuatan dan kemahiran mental. SPQ20 mengandungi dua puluh dimensi kekuatan dan kemahiran mental dalam sukan seperti berikut:

\begin{tabular}{|c|c|}
\hline $\begin{array}{l}\text { Dimensi Kemahiran } \\
\text { Mental }\end{array}$ & Penerangan \\
\hline Pencapaian & $\begin{array}{l}\text { Bermotivasi untuk berjaya, membuat pengorbanan untuk mencapai } \\
\text { kecemerlangan. }\end{array}$ \\
\hline Kebolehsuaian & $\begin{array}{l}\text { Terbuka kepada idea dan cadangan baru, sentiasa mengikuti } \\
\text { perkembangan teknikal. }\end{array}$ \\
\hline Daya Saing & $\begin{array}{l}\text { Gemar bersaing, mahu menjadi lebih baik daripada yang lain, } \\
\text { bertujuan untuk menang. }\end{array}$ \\
\hline Teliti & $\begin{array}{l}\text { Melakukan persediaan dengan teliti, menunjukkan disiplin diri, } \\
\text { kekal dengan perancangan }\end{array}$ \\
\hline Visualisasi & $\begin{array}{l}\text { Menggunakan kaedah imageri untuk mempraktikkan prestasi, kekal } \\
\text { tenang, dan lakukan dengan baik. }\end{array}$ \\
\hline Intuisi & $\begin{array}{l}\text { Menggunakan naluri dan gerak hati untuk membantu membuat } \\
\text { keputusan berkenaan prestasi. }\end{array}$ \\
\hline
\end{tabular}




\begin{tabular}{|c|c|}
\hline Penetapan Matlamat & $\begin{array}{l}\text { Menetapkan keutamaan dan matlamat untuk membantu mengurus } \\
\text { pembelajaran dan perkembangan diri. }\end{array}$ \\
\hline Menguruskan Tekanan & $\begin{array}{l}\text { Menangani kebimbangan dan stres sebelum berlaku peristiwa } \\
\text { penting (pertandingan) dengan cara yang berkesan. }\end{array}$ \\
\hline Keberkesanan Kendiri & Memaparkan keyakinan diri dan pulih dari kesukaran dengan cepat. \\
\hline Takut akan kegagalan & $\begin{array}{l}\text { Mengurus rasa takut terhadap kegagalan, membiarkan orang lain } \\
\text { jatuh, dan tidak perlu mencapai apa yang diharapkan. }\end{array}$ \\
\hline Aliran/Flow & $\begin{array}{l}\text { Menunjukkan keupayaan untuk menyerapkan diri sepenuhnya } \\
\text { dalam aksi yang dilakukan semasa perlawanan, dan bermain dalan } \\
\text { zon sendiri. }\end{array}$ \\
\hline Pengurusan Stres & $\begin{array}{l}\text { Menguruskan stres dengan berkesan, mengikuti gaya hidup yang } \\
\text { sihat. }\end{array}$ \\
\hline Emosi & Mengatur perasaan dan emosi untuk memaksimumkan prestasi. \\
\hline Bicara Kendiri & $\begin{array}{l}\text { Bercakap secara positif terhadap diri sendiri untuk mengekalkan } \\
\text { ketenangan, kekal fokus, dan lakukan dengan baik. }\end{array}$ \\
\hline Kesedaran Kendiri & $\begin{array}{l}\text { Mendapatkan maklum balas tentang perubahan diri, dan } \\
\text { mempunyai kesedaran tentang tahap kekuatan dan kelemahan diri. }\end{array}$ \\
\hline Etika & $\begin{array}{l}\text { Mempamerkan prinsip yang kukuh, berkelakuan secara beretika, } \\
\text { dan menunjukkan semanagat kesukanan. }\end{array}$ \\
\hline Empati & $\begin{array}{l}\text { Mendengar dan menunjukkan keprihatinan terhadap pandangan } \\
\text { dan perasaan orang lain. }\end{array}$ \\
\hline Hubungan & Membina hubungan, berbual, dan bersosial dengan atlet lain. \\
\hline Keagresifan & $\begin{array}{l}\text { Menunjukkan tingkah laku yang tegas, cenderung untuk mengatasi } \\
\text { dan menakut-nakutkan pihak lawan. }\end{array}$ \\
\hline Kuasa & $\begin{array}{l}\text { Gemar menguasai orang lain, bercita-cita untuk menjawat } \\
\text { kedudukan sebagai pemimpin. }\end{array}$ \\
\hline
\end{tabular}

Kesemua dimensi merangkumi empat domain utama iaitu pencapaian dan persaingan, keyakinan dan resilien, interaksi dan semangat kesukanan, serta kuasa dan keagresifan. Soal selidik ini juga mengukur kecenderungan atlet dalam dua jenis matrik iaitu kemahiran mental dan potensi kepemimpinan. Matrik kemahiran mental mengandungi empat jenis kecenderungan iaitu tense contestant, easygoing contestant, tense achiever dan easygoing achiever. Manakala matrik potensi kepemimpinan terdiri daripada empat jenis kecenderungan iaitu individual player, controlling captain, team player dan democratic captain. Maklum balas data SPQ20 adalah menggunakan sistem penskoran Standard Ten (sten). Intepretasi data SPQ20 adalah berdasarkan skor sten yang dipecahkan kepada tiga kategori menggunakan sistem rating penilaian Traffic Light - Red Amber Green (RAG) seperti berikut: 


\begin{tabular}{|c|c|c|c|}
\hline Skor Sten & Rating RAG & $\begin{array}{c}\text { Tahap Kemahiran } \\
\text { Mental }\end{array}$ & Status Perkembangan \\
\hline Lebih daripada 7.01 & Hijau (Green) & Tinggi & $\begin{array}{c}\text { Kemahiran digunakan } \\
\text { dengan baik }\end{array}$ \\
\hline 4.01 hingga 7 & Kuning (Amber) & Sederhana & $\begin{array}{c}\text { Kemahiran perlu } \\
\text { ditingkatkan }\end{array}$ \\
\hline Kurang daripada 4 & Merah $(R e d)$ & Rendah & Kemahiran perlu dibentuk \\
\hline
\end{tabular}

Soal selidik SPQ mengandungi 168 item soalan. Menurut (MySkillProfile, 2016) tempoh pentadbiran soal selidik adalah antara 15 hingga 20 minit pada sesuatu masa. Nilai kebolehpercayaan SPQ20 adalah antara 0.6 hingga 0.8. Kesahan dan juga penilaian terhadap SPQ20 telah dilakukan dalam kalangan professional dan atlet amatur. Kajian kesahan konstruk telah dilakukan sekali dengan kesahan sejajar dan telah disahkan oleh Buros Center for Testing (2013) dan British Psychological Society Psychological Testing Center (2012).

\section{DAPATAN KAJIAN}

\section{Tahap Kemahiran Mental dalam Empat Domain Utama}

Jadual 1 menjelaskan tahap kemahiran mental pasukan Boling Ten-Pin MSSM 2018 negeri Perak. Kesemua domain kemahiran mental berada tahap yang sederhana berdasarkan rating RAG iaitu pencapaian dan persaingan (5.50 \pm 1.37$)$, keyakinan dan resilien (5.49 \pm 1.53$)$, interaksi dan semangat kesukanan (5.50 \pm 1.50$)$, dan kuasa dan keagresifan (5.51 \pm 1.38$)$.

Jadual 1: Tahap Kemahiran Mental

\begin{tabular}{lccc}
\hline Domain Kemahiran Mental & $N$ & $M$ & $S D$ \\
\hline Pencapaian dan Persaingan & 24 & 5.50 & 1.37 \\
Keyakinan dan Resilien & 24 & 5.49 & 1.53 \\
Interaksi dan Semangat Kesukanan & 24 & 5.50 & 1.50 \\
Kuasa dan Keagresifan & 24 & 5.51 & 1.38 \\
\hline
\end{tabular}

Jadual 2 menjelaskan kekerapan kecenderungan tahap kemahiran mental berdasarkan rating RAG. Berdasarkan Jadual 2, didapati majaroti ahli pasukan cenderung terhadap rating berwarna kuning. Rating kuning menggambarkan tahap kecenderungan bagi setiap domain kemahiran mental berada pada peringkat sederhana.

Jadual 2: Kekerapan subjek dalam domain kemahiran mental berdasarkan berdasarkan rating RAG

\begin{tabular}{lccc}
\hline \multirow{2}{*}{ Domain Kemahiran Mental } & Hijau & Kuning & Merah \\
\cline { 2 - 4 } & $f(\%)$ & $f(\%)$ & $f(\%)$ \\
\hline Pencapaian dan Persaingan & $3(12.5 \%)$ & $17(70.8 \%)$ & $4(16.7 \%)$ \\
Keyakinan dan Resilien & $3(12.5 \%)$ & $19(79.2 \%)$ & $2(8.3 \%)$ \\
\hline
\end{tabular}




\begin{tabular}{llll}
\hline Interaksi dan Semangat Kesukanan & $3(12.5 \%)$ & $17(70.8 \%)$ & $4(16.7 \%)$ \\
Kuasa dan Keagresifan & $5(20.8 \%)$ & $15(62.5 \%)$ & $4(16.7 \%)$ \\
\hline
\end{tabular}

\section{Kecenderungan Matrik Kemahiran Mental}

Jadual 3 menjelaskan kekerapan ahli pasukan Boling Ten-Pin MSSM 2018 negeri Perak berdasarkan matrik kemahiran mental. Matrik kemahiran mental adalah gabungan skor interaksi dan semangat kesukanan, dan skor kuasa dan keagresifan.Dapatan menunjukkan paling ramai atlet adalah dalam golongan democratic captain iaitu seramai lapan orang (33.3\%). Manakala paling sedikit atlet yang cenderung dalam golongan individual player iaitu seramai empat orang (16.7\%).

Jadual 3: Kecenderungan Matrik kemahiran mental

\begin{tabular}{cc}
\hline Matrik Kemahiran Mental & $\mathrm{f}(\%)$ \\
\hline Tense Contestant & $6(25.0 \%)$ \\
Tense Achiever & $2(8.3 \%)$ \\
Confident Achiever & $13(54.2 \%)$ \\
Easygoing Contestant & $3(12.5 \%)$ \\
Jumlah & $24(100.0 \%)$ \\
\hline
\end{tabular}

\section{Kecenderungan Matrik Potensi Kepemimpinan}

Jadual 4 pula menjelaskan kekerapan ahli pasukan Boling Ten-Pin MSSM 2018 negeri Perak berdasarkan matrik potensi kepemimpinan. Matrik potensi kepemimpinan adalah gabungan skor pencapaian dan persaingan, dan skor keyakinan dan resilien. Dapatan menunjukkan paling ramai atlet adalah dalam golongan confident achiever iaitu seramai 13 orang (54.2\%). Manakala paling sedikit atlet yang cenderung dalam golongan tense achiever iaitu seramai dua orang (8.3\%).

Jadual 4: Kecenderungan Matrik Potensi Kepemimpinan

\begin{tabular}{cc}
\hline Matrik Kemahiran Mental & $\mathrm{f}(\%)$ \\
\hline Individual Player & $4(16.7 \%)$ \\
Team Player & $6(25.0 \%)$ \\
Democratic Captain & $8(33.3 \%)$ \\
Controlling Captain & $6(25.0 \%)$ \\
Jumlah & $24(100.0 \%)$ \\
\hline
\end{tabular}

\section{PERBINCANGAN}

Domain pencapaian dan persaingan mengandungi dimensi tret personaliti dan kemahiran mental. Atlet yang mendapat skor tinggi dalam domain ini menunjukkan motivasi pencapaian yang tinggi di samping sikap persaingan, kesedaran moral dan penyesuaian diri, serta. Ini adalah ciri-ciri tret 
personaliti yang baik untuk seorang atlet, disamping memiliki ciri-ciri keyakinan yang tinggi terhadap penggunaan teknik kemahiran mental seperti imageri dan penetapan matlamat bagi mencapai prestasi kemahiran mental yang diharapkan, serta penggunaan naluri dan gerak hati yang berkesan. Domain keyakinan dan resilien pula mengandungi ciri-ciri tret personaliti yang menjurus ke arah kestabilan emosi, kecerdasan emosi dan kemahiran mental. Atlet yang mendapat skor tingi dalam domain ini memiliki tahap kesedaran kendiri yang tinggi, keyakinan yang teguh, berupaya mengawal selia perasaan dan emosi, menguruskan ketakutan akibat kegagalan, menangani tekanan dan mengekalkan tumpuan.

Seterusnya adalah domain interaksi dan semangat kesukanan yang menggambarkan tahap kemahiran sosial dan prinsip etika dalam sukan. Atlet yang mendapat skor tinggi dalam domain ini adalah individu yang menghargai keadilan, integriti, tanggungjawab dan penghormatan. Atlet sedemikian berminat dengan rakan sepasukan, sukakan hubungan yang baik antara juruatih dan rakan sepasukan. Manakala bagi domain kuasa dan keagresifan, menggambarkan kecenderungan atlet untuk menguasai rakan sepasukan dan sikap agresif yang ditunjukkan. Atlet yang mendapat skor tinggi dalam domain ini sentiasa bersedia untuk maju ke hadapan, membuktikan apa yang dikata dan menjadi contoh kepada rakan sepasukan.

Walau bagaimanapun, berdasarkan kajian yang telah dijalankan, secara keseluruhan ahli pasukan Boling Ten-Pin MSSM 2018 negeri Perak telah menunjukkan tahap kemahiran mental pada rating RAG berwarna kuning dalam ke semua domain. Rating kuning menunjukkan tahap kemahiran berada pada paras sederhana. Ini menunjukkan bahawa atlet perlu berusaha meningkatkan lagi kesemua tahap domain kemahiran mental tersebut (MySkillProfile, 2016). Menurut Jones et al. (2002), untuk menjadi seorang atlit elit perlulah kekal dan lebih superior dalam keempat-empat domain yang dinyatakan.

Walau bagaimanapun, secara keseluruhan atlet dalam kajian ini menunjukkan kecenderungan yang tinggi sebagai confident achiever iaitu seramai 13 orang (54.2\%). Ini menggambarkan bahawa paling ramai atlet dalam pasukan ini meletakkan skor yang tinggi dalam aspk persaingan dan resilien mental. Atlet merasa positif terhadap perlawanan mereka, memiliki kekuatan mental, motivasi pencapaian dan harapan untuk mendapatkan kemenangan. Manakala dari aspek potensi kepemimpinan, paling ramai atlet adalah dalam golongan democratic captain iaitu seramai lapan orang (33.3\%). Kumpulan atlet ini menunjukkan kecenderungan untuk dimotivasikan oleh kuasa, status personal dan prestij, dan keperluan untuk berkawan. Mereka juga suka untuk memimpin dan berharap mendapat pengiktirafan dari orang lain.

Sehubungan itu, kajian ini diharap dapat memberi sedikit sebanyak gambaran tentang kepentingan menilai tahap kemahiran mental atlet, cara penggunan alat ukur yang bersesuaian bagi mendapatkan maklumat berkaitan tahap kemahiran mental, dan cara pelaporan dapatan kajian bagi tujuan penambahbaikan. Justeru pihak jurulatih dan pengurusan pasukan yang menerima laporan dapatan kajian sebegini diharap dapat memberi fokus terhadap aspek kelemahan (rating merah dan kuning) dalam kemahiran mental terutama yang boleh mendatangkan kesan buruk ke atas prestasi fizikal. Di samping itu aspek kekuatan juga tidak boleh dipinggirkan. Kajian menunjukkan bahawa keberkesanan prestasi adalah disebabkan oleh kekuatan mental yang dimiliki atlet, dan strategi 
alternatif dalam meningkatkan prestasi adalah dengan memberi konsentrasi ke atas kekuatan individu itu sendiri (MySkillProfile, 2016).

\section{RUJUKAN}

Ary, D., Jacobs, L. C., \& Razavieh, A. (2010). Introduction to research in education. $8^{\text {th }}$ Ed. Wadsworth: Cengage Learning.

Butt, J., Weinberg, R. \& Culp, B. (2010). Exploring mental toughness in NCAA athletes. Journal of Intercollegiate Sport, 3(2), 316-332.

Clough, P. J., Earle, K., \& Sewell, D. (2002). Mental toughness: the concept and its measurement. In I. Cockerill (Ed.), Solutions in Sport Psychology (pp. 32-43). London: Thomson.

Elferink-Gemser, M. T., Visscher, C., Lemmink, K., \& Mulder, T. H. (2004). Relation between multidimensional performance characteristics and level of performance level in talented youth field hockey players. Journal of Sports Science, 22,1053-1063.

Fletcher, D., \& Sarkar, M. (2012). A grounded theory of psychological resilience in Olympic champions. Psychology of Sport and Exercise, 13, 669-678.

Gardner, F. L. \& Moore, Z. E. (2006). Clinical sport psychology. Champaign, IL: Human Kinetics.

Gee, C.J. (2010). How Does Sport Psychology Actually Improve Athletic Performance? A Framework to Facilitate Athletes' and Coaches' Understanding. Behavior Modification, 34(5), 386-402.

Gould, D., Dieffenbach, K., \& Moffett, A. (2002). Psychological Characteristics and Their Development in Olympic Champions. Journal of Applied Sport Psychology, 14, 172-204.

Hardy, L., Jones, G., \& Gould, D. (1996). Understanding psychological preparation for sport: Theory and practice of elite performers. New York: Wiley.

Hodge, K. (2007). Sport motivation: Training your mind for peak performance. Auckland, New Zealand: Reed Books.

Hollings, S. C., Mallett, C. J., \& Hume, P.A. (2014). The transition from elite junior track-and-field athlete to successful senior athlete: Why some do, why others don "et. International Journal of Sport Science \& Coaching, 9(3), 457-471.

Jones, G., Hanton, S., \& Connaughton, D. (2007). A framework of mental toughness in the world's best performers. The Sport Psychologist, 21, 243-264.

Jones, G., Hanton, S., \& Connaughton, D. (2002). What is this thing called mental toughness? An investigation of elite sport performers. Journal of Applied Sport Psychology, 14, 205-218.

Kruger, A., Pienaar, A. E., Plessis, E. D. \& Van Rensburg, L. J. (2012). The importance of psychological characteristics in potentially talented adolescent long distance runners. African Journal for Physical, Health Education, Recreation and Dance, 18(2), 413-422.

Kumar, P. \& Shirotriya, A. K. (2010). "Sports psychology"e a crucial ingredient for athlete success: Conceptual view. British Journal of Sports Medicine, 44(1), i55-i56.

Lesyk, J. (1998). The nine mental skills of successful athletes: A holistic model for assessingand teaching mental skills to athletes. Workshop presented at the Annual Conference of the Association for the Advancement of Applied Sport Psychology (AAASP). Hyanis, MA, USA. 
MySkillProfile. (2016). Sport Personality Questionnaire: User Manual. Retrieved from https://www.myskillsprofile.com/tests/spq20.

Nelson, D. J. (2008). The attitudes of coaches toward sport psychology consultation. Unpublished doctoral dissertation, Cappella University.

Noakes, T. (2003). Lore of running $\left(4^{\text {th }}\right.$. ed.). Champaign, IL: Human Kinetics.

Orlick, T. (2000). In pursuit of excellence ( $3^{\text {rd }}$. ed.).Champaign, IL: Human Kinetics.

Pieterse, J.J. \& Potgieter, J.R. (2006). The effect of sport-psychological intervention techniques on the performance of middle-distance athletes). South African Journal for Research in Sport, Physical Education and Recreation, 28(1), 85-99.

Porter, K. (2003). The mental athlete. Champaign, IL: Human Kinetics.

Taylor, J. (1993). The mental edge for competitive sports ( $3^{\text {rd }}$. ed.). Aspen, CO: Alpine Taylor Consulting.

Vernacchia, R. A., Mcguire, R. T., Reardon, J. P., \& Templin, D. P. (2000). Psychological characteristics of Olympic track and field athletes. International Journal of Sport Psychology, 31(1), 5-23

Weinberg, R. S., \& Gould, D. (2011). Foundations of sport and exercise psychology. Champaign, Human Kinetics.

$\risingdotseq$ Nur Haziyanti Mohamad Khalid

Fakulti Sains Sukan dan Kejurulatihan, Universiti Pendidikan Sultan Idris, Tg Malim, Perak,

Malaysia

Email: nur.haziyanti@fsskj.upsi.edu.my 